\title{
Freqüência de soropositividade para antígenos de Toxocara canis em crianças de classes sociais diferentes
}

\author{
Frequency of seropositivity to Toxocara canis in children \\ of different socioeconomic strata
}

\begin{abstract}
Dioclécio Campos Júnior ${ }^{1}$, Guita Rubinsky Elefant ${ }^{2}$, Elisabeth Ourique de Melo e Silva², Leonora Gandolfi ${ }^{1}$, Cristina Miuki Abe Jacob ${ }^{3}$, Aline Tofeti ${ }^{1}$ e Riccardo Pratesi ${ }^{1}$
\end{abstract}

\begin{abstract}
Resumo Para estudar a freqüência da infecção pelo Toxocara canis em crianças de classes sociais diferentes de Brasília, Brasil, foram testados soros de 602 crianças de ambos os sexos, de 1 a 12 anos, distribuídas em dois grupos representativos de condições socioeconômicas distintas. As amostras do primeiro grupo foram obtidas em laboratório público que atende bairros pobres. As do segundo grupo foram colhidas em laboratório privado, que serve à classe média. Os anticorpos anti-Toxocara foram detectados pelo método ELISA, com antígenos de Toxocara canis, e absorção com antígenos do Ascaris suum. A prevalência de soropositividade foi de $21,8 \%$ (66/302) no primeiro grupo e de $3 \%(9 / 300)$ no segundo $(p<0,0001)$. Não houve diferença quanto ao gênero ou idade das crianças. Os resultados sugerem significativa prevalência de toxocaríase na população infantil de Brasília, com predomínio nas classes sociais menos favorecidas economicamente.
\end{abstract}

Palavras-chaves: Toxocaríase. Larva migrans visceral. Toxocara canis. ELISA.

Abstract Frequency of seropositivity for Toxocara in children from different socioeconomic strata in the city of Brasilia (Brazil) was measured. Six hundred and two children of both sexes, aged one to 12 years were distributed in two socioeconomically distinct groups. The samples of sera of the first group were obtained from blood drawn for routine tests in the laboratory of a public hospital attending children from low-income families. Samples from the second group were obtained from private laboratories attending children from middle-class families. Antitoxocara antibodies were detected by ELISA, using Toxocara canis excretory-secretory antigens previously absorbed with Ascaris suum extract. The prevalence of seropositivity was $21.8 \%$ (66/302) in the first group and $3 \%(9 / 300)$ in the second $(p<0.0001)$. No differences in frequency according to age or sex could be detected. Our results suggest a high prevalence of childhood toxocariasis in Brasilia, with children from lower income brackets being the most affected.

Key-words: Toxocariasis. Visceral larva migrans. Toxocara canis. ELISA

A toxocaríase é uma zoonose muito difundida em todo o mundo ${ }^{17}$. Trata-se da infecção do hospedeiro humano pelas larvas de Toxocara canis ou de Toxocara cati, nematóides que parasitam cães ou gatos. Descrita por Beaver et $\mathrm{al}^{4}$, em 1952, a toxocaríase é também conhecida por síndrome da larva migrans visceral.

O parasitismo humano é conseqüência da ingestão acidental de ovos embrionados de Toxocara, eliminados no solo juntamente com as fezes dos seus hospedeiros naturais. A larva liberada no intestino delgado penetra a parede intestinal migrando para as vísceras em geral, onde exerce suas ações patogênicas. Entre os múltiplos quadros clínicos que produz, incluindo os casos assintomáticos, salientam-se manifestações alérgicas, hipereosinofilia, fraqueza crônica, dor abdominal, além da forma visceral clássica da doença, marcada pelo comprometimento hepático e pulmonar, bem como da localização ocular, considerada uma das causas mais freqüentes de cegueira na criança ${ }^{18}$. Representa um problema de saúde pública de grande relevância que não tem merecido os estudos e a intervenção necessária para a redução do seu impacto populacional.

1. Departamento de Medicina da Criança e do Adolescente da Faculdade de Medicina da Universidade de Brasília, Brasília, DF. 2. Laboratório de Imunologia e Biologia Molecular do Instituto de Medicina Tropical de São Paulo, São Paulo, SP. 3. Departamento de Pediatria do Instituto da Criança da Universidade de São Paulo, São Paulo, SP.

Endereço para correspondência: Dr. Dioclécio Campos Júnior. SQS 305, Bloco B Apto 305, 70352-020 Brasília, DF.

Tel: 5561 242-9063/9966-2658; Fax :55 61 242-3873

e-mail : dicampos@terra.com.br

Recebido para publicação em 10/9/2002.

Aceito em 26/6/2003 
O diagnóstico da toxocaríase humana baseia-se essencialmente em testes imunológicos por ser muito difícil ${ }^{16}$ a demonstração das larvas de Toxocara sp em material de biópsia. Os estudos da freqüência de soropositividade para antígenos de Toxocara $s p$ possibilitam a delimitação da importância desta zoonose em determinada região, prestando-se como instrumento valioso para fundamentar a adoção de medidas educativas e preventivas.

A maioria dos estudos feitos em diversas regiões do mundo não leva em consideração possíveis diferenças decorrentes das desigualdades sociais que diferenciam segmentos populacionais de um mesmo território. Dadas as características do ciclo de transmissão da toxocaríase, é possível que as crianças pertencentes às classes pobres, vivendo em condições higiênicas desfavoráveis, mais expostas ao contacto com o solo contaminado, sejam mais suscetíveis às conseqüências deste parasitismo.

O presente trabalho teve por objetivo comparar a freqüência de soro-positividade contra antígenos de Toxocara canis em crianças que habitam a periferia pobre de Brasília com a das crianças que vivem nos condomínios e quadras residenciais de classe média da cidade. O projeto foi aprovado pelo Comitê de Ética de Pesquisa em Humanos da Faculdade de Medicina da Universidade de Brasília.

\section{PACIENTES E MÉTODOS}

O modelo escolhido foi o do estudo transversal para a análise de freqüência da soropositividade ao antígeno de T. canis.

A amostra consistiu de dois grupos de crianças. $O$ primeiro, denominado Grupo A, foi constituído por 302 crianças atendidas no ambulatório do Hospital Universitário de Brasília. Reúne crianças representativas da população de baixo nível socioeconômico, usuária do sistema público de saúde. O segundo grupo, denominado Grupo B, foi composto por 300 crianças atendidas em clínicas e laboratórios particulares ou de planos de saúde, caracterizando-se, conseqüentemente, como uma amostra populacional de nível socioeconômico elevado. Em cada grupo foram incluídas crianças de 1 a 12 anos de idade, de ambos os sexos, submetidas a coleta de sangue para a realização de diferentes exames laboratoriais, solicitados para esclarecimento de sinais e sintomas diversos, sem presunção diagnóstica de toxocaríase.

A determinação da presença de anticorpos anti- T. canis foi feita segundo a técnica de ELISA descrita a seguir.

Antígenos. Para o teste imunoenzimático ELISA (Enzyme Linked Immunosorbent Assay) foi utilizado antígeno de Excreção e Secreção (TES) de larvas de Toxocara canis obtido segundo De Savigny ${ }^{67}$, com algumas modificações ${ }^{9}$. As larvas foram liberadas dos ovos e cultivadas em meio de Eagle, isento de soro. O antígeno foi acrescido de inibidor de protease (Phenyl-methyl-sulphonyl-fluoride) 200mM $(5 \mu \mathrm{l} / \mathrm{ml}$ de meio coletado), dialisado em água destilada, centrifugado a $4^{\circ} \mathrm{C}$, a $15.000 \mathrm{rpm}$, por 60min, e filtrado em membrana Millipore de $0,22 \mu$. Foi feita a dosagem protéica pelo método de $\operatorname{Lowry}^{12}(630 \mu / \mathrm{ml})$ e o antígeno foi conservado em alíquotas a $-20^{\circ}$.

Para a absorção dos soros, foi utilizado extrato antigênico de vermes de Ascaris suum, obtidos do intestino de suínos, segundo Kanamura et $\mathrm{al}^{11}$, com modificações. Os vermes foram macerados em graal em água destilada, acrescidos de $\mathrm{NaOH}(1 \mathrm{M})$ numa proporção de $1,5 \mathrm{ml} / 8,5 \mathrm{ml}$ de extrato. Neutralizou-se a solução com $\mathrm{HCl} 6 \mathrm{M}$ e centrifugou-se a $2.000 \mathrm{rpm}$, por 10 minutos. Foi feita a dosagem protéica pelo método de Lowry ${ }^{12}(5 \mathrm{mg} / \mathrm{ml})$, a seguir a solução foi filtrada em papel Whatman, e foi acrescida de $1 / 3$ do seu volume de éter para que fosse efetuada a deslipidação. A camada etérea foi removida. $O$ extrato antigênico foi

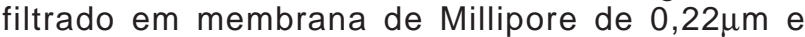
conservado em alíquotas a $-20^{\circ} \mathrm{C}$.

Ensaio sorológico. Teste Imunoenzimático ELISA$\operatorname{lgG}$, baseado no método descrito por de Savigny ${ }^{8}$, com modificações ${ }^{9}$. Placas de poliestireno com fundo em $U$ foram sensibilizadas com $0,130 \mu \mathrm{g}$ de antígeno TES em solução tampão carbonato-bicarbonato $0,1 \mathrm{M}, \mathrm{pH}$ 9,6. Para o bloqueio foi utilizada solução de soro albumina bovina a $1 \%$ em solução salina tamponada com fosfatos, contendo Tween-20 a 0,05\% (PBS-T). Os soros foram absorvidos a 1/160 em solução de Ascaris suum a 1/200 em PBS-T, por 30 minutos a $37^{\circ} \mathrm{C}$ e a seguir foi feita a diluição para 1/ 320 em PBS-T, e testados em duplicata. O conjugado (antiIgG humano marcado com peroxidase- Biolab) foi diluído a 1/4000 em PBS-T. Como solução cromógena, utilizouse solução de ortofenilenodiamina a 0,01\%, em tampão acetato $0,05 \mathrm{M}, \mathrm{pH} 4,5$ acrescido de peróxido de hidrogênio $30 \%$ na concentração final de $0,05 \%$. Após 20 minutos à temperatura ambiente e isento de luz, a reação foi bloqueada pela adição de ácido sulfúrico $2 \mathrm{~N}$. A densidade óptica (DO) foi obtida a $492 \mathrm{~nm}$, em aparelho Titertek Multiscan MMC/340. Em todos os testes foram incluídos soros padrão reagente e não reagente e um soro limiar de reatividade (SLR). Amostras com DOs acima dos valores das DOs do SLR foram consideradas reagentes.

Utilizou-se o programa Epi-info, versão 6, para os tratamentos estatísticos que consistiram no cálculo do quiquadrado para comparação de prevalências, admitindose como limite de significância o valor de p inferior a 0,05.

\section{RESULTADOS}

As características das crianças nos dois grupos estão apresentadas na Tabela 1 , na qual se verifica composição homogênea quanto ao gênero e as idades das crianças cujos soros foram testados. 
A Tabela 2 reúne os resultados dos testes realizados nos dois grupos de crianças e a significância estatística das diferenças evidenciadas. Foram testadas 602 amostras de soros. Dos 302 soros testados no grupo A, constituído por crianças de baixo nível sócio econômico, 66(21,8\%) foram positivos, enquanto que dos soros extraídos do sangue de crianças do grupo $B$, pertencentes a estrato de nível socioeconômico diferenciado, apenas 9(3\%) resultaram positivos.

A distribuição da soropositividade em função do gênero é mostrada na Tabela 3. Não houve diferença de prevalência em função das idades das crianças que foram objeto dos testes realizados.

Tabela 1 - Composição dos grupos $A$ e $B$ segundo gênero e idade das crianças estudadas.

\begin{tabular}{|c|c|c|c|c|c|c|}
\hline \multirow[b]{2}{*}{ Grupo } & \multicolumn{2}{|c|}{ Masculino } & \multicolumn{2}{|c|}{ Feminino } & \multirow[t]{2}{*}{ Total } & \multirow{2}{*}{$\begin{array}{c}\text { Média de idade } \\
\text { (anos) }\end{array}$} \\
\hline & $\mathrm{n}$ & $\%$ & $\mathrm{n}$ & $\%$ & & \\
\hline A & 147 & 48,7 & 155 & 51,3 & 302 & 6,6 \\
\hline B & 167 & 55,7 & 133 & 44,3 & 300 & 5,4 \\
\hline
\end{tabular}

Tabela 2 - Prevalência de soropositividade ao T. canis em crianças de grupos sociais diferentes.

\begin{tabular}{lcccc}
\hline $\begin{array}{c}\text { Grupo } \\
\text { ELISA-IgG } \\
\text { positivo }\end{array}$ & $\begin{array}{c}\text { ELISA-IgG } \\
\text { negativo }\end{array}$ & $\begin{array}{c}\text { Total } \\
(\%)\end{array}$ & Prevalência \\
\hline B & 66 & 236 & 302 & 21,8 \\
\hline
\end{tabular}

Razão de prevalência : 8.20

Intervalo de confiança de $95 \%$

Qui-quadrado $=51,39$

$\mathrm{p}<0,0001$
Tabela 3 - Distribuição da soropositividade ao T. canis em função do gênero das crianças em cada grupo estudado.

\begin{tabular}{lrrrrrrr}
\hline & \multicolumn{3}{c}{ Masculino } & & \multicolumn{3}{c}{ Feminino } \\
\cline { 2 - 4 } \cline { 6 - 8 } Grupo & $n$ & ELISA + & $\%$ & & $n$ & ELISA - & $\%$ \\
\hline A & 147 & 33 & 22,40 & & 155 & 33 & 21,29 \\
B & 167 & 6 & 3,60 & & 133 & 3 & 2,25 \\
\hline
\end{tabular}

Teste de Fisher $p>0,05$

\section{DISCUSSÃO}

A preocupação com a prevalência de toxocaríase na população infantil tem justificado a realização de inquéritos sorológicos em vários países. Os resultados apontam, na maioria dos estudos efetuados, evidências significativas da prevalência desta zoonose, independentemente do nível socioeconômico das populações estudadas. Ademais, a associação entre toxocaríase e a presença de sintomas clínicos diversos e potencialmente graves na criança reforça a importância de se considerar esta doença como um importante problema de saúde pública ${ }^{19}$.

A prevalência de toxocaríase na cidade de Brasília não é conhecida. No entanto, como a criação de cães domésticos tornou-se prática crescente em todos os setores da cidade, tanto naqueles habitados por população economicamente bem situada quanto naqueles em que vivem os contingentes mais pobres dos seus moradores, é de se supor que a toxocaríase seja também uma nosologia prevalente nesta cidade.

O critério empregado para a separação dos dois grupos populacionais selecionados foi simples e objetivo tendo em vista que o sistema público de saúde é utilizado quase que exclusivamente pelas populações pobres do país, enquanto as instituições privadas atendem unicamente a demanda dos segmentos populacionais de classe média. Assim, os dois grupos estudados são representativos das condições de vida de seus integrantes e se prestam bem à comparação de freqüências dado que são homogêneos no tocante às demais variáveis analisadas, como se observa na Tabela 1. No primeiro deles, estão as crianças que, em geral, vivem em locais desprovidos de infra-estrutura sanitária, residindo em casas de construção precária, sem condições adequadas de higiene, convivendo com grande número de cães que eliminam suas fezes sobre o solo, na proximidade das casas. No segundo grupo estão incluídas as crianças que residem geralmente em apartamentos dotados de condições ideais de saneamento, localizados em áreas privilegiadas do espaço urbano de Brasília. Embora convivam também com número significativo de cães, a possibilidade de ingestão de ovos embrionados de T. canis é certamente menor neste grupo, seja por conta de hábitos higiênicos mais desenvolvidos, seja pelo tratamento regular dos cães com medicamentos antiparasitários. É possível, ainda, que o melhor estado de nutrição destas crianças represente, também, um fator de proteção contra a penetração intestinal das larvas.

Os resultados obtidos nos testes sorológicos realizados neste trabalho revelam diferença significativa entre a freqüência de soropositividade ao T. canis observada em crianças procedentes dos bairros pobres de Brasília e a que se constata nas crianças residentes nos setores mais ricos da cidade, conforme se observa na Tabela 2. A possibilidade de reação cruzada com antígenos de outros parasitas - causa de erros diagnósticos conhecida -, foi descartada, no presente estudo, pela absorção preliminar das amostras sorológicas com antígenos do A. suum, 
nematóide relacionado antigenicamente com o Ascaris lumbricoides, que é um parasita intestinal comum em crianças, e cuja infestação poderia falsear o teste de ELISA para identificação de anticorpos contra o T. canis ${ }^{15}$.

Embora a amostra populacional estudada não permita definir a prevalência da toxocaríase para a população de Brasília, os resultados apontam para provável relevância desta zoonose no Distrito Federal. De fato, a freqüência de $21,8 \%$ encontrada nas crianças da periferia de Brasília compara-se com a de $37,9 \%$ em região subtropical da Argentina ${ }^{2} ; 39 \%$ na cidade de la Plata ${ }^{17}$; de $29,6 \%$ na Nigéria $^{1} ; 22 \%$ na região oeste da França ${ }^{10} ; 30 \%$ na periferia de Caracas $^{13} ; 27,2 \%$ na população escolar de Trinidad ${ }^{3}$. Na maior parte desses estudos, os testes sorológicos foram feitos em crianças previamente triadas pelo critério da hipereosinofilia ou da presença de sinais clínicos sugestivos de toxocaríase, diferentemente do presente estudo, que não utilizou qualquer um desses critérios.

Os resultados obtidos mostram, com elevada significância, o impacto das desigualdades sociais como fator determinante da alta prevalência desta doença parasitária nas populações mais pobres. Neste sentido, os dados encontrados estão de acordo com Cilla e cols ${ }^{5}$, que referem prevalência de soropositividade para T. canis de $0 \%$ em crianças de classe média e de $37 \%$ em crianças pobres de uma região do país Basco. No estudo realizado por Silva FM e cols ${ }^{18}$ em 100 crianças escolhidas aleatoriamente entre a população infantil internada em hospital da cidade de Vitória, estado do Espírito Santo, no Brasil, a prevalência foi de 39\%. Estes autores não observaram diferença na soropositividade para T. canis entre crianças oriundas de classes sociais distintas porque a amostra estudada foi pequena e, além disto, o hospital atende unicamente pacientes do sistema público de saúde, não permitindo a caracterização de dois grupos populacionais de níveis socioeconômicos distintos, como foi feito no presente trabalho. Nos dois grupos por nós estudados, a freqüência de soropositividade para Toxocara canis não apresentou diferença significativa quanto às faixas etárias, nem quanto ao sexo das crianças, como mostra a Tabela 3. Esta observação confirma conclusões de estudo semelhante realizado no Brasil ${ }^{18}$.

Considerando que os resultados encontrados sugerem forte indício de que a toxocaríase seja um problema importante de saúde para a população do Distrito Federal, torna-se necessária a realização de um inquérito sorológico populacional que permita dimensionar, com o rigor metodológico desejável, a verdadeira prevalência desta zoonose na capital da república. Por outro lado, a demonstração de que a freqüência de soropositividade para antígenos de T. canis é sete vezes maior nas crianças que habitam a periferia de Brasília impõe a adoção de política pública que privilegie tais populações, protegendo-as, em caráter prioritário, de uma doença responsável por sintomas polimorfos e morbidade potencialmente grave.

\section{REFERÊNCIAS BIBLIOGRÁFICAS}

1. Ajayi OO, Duhlinska DD, Agwale SM, Njoku M. Frequency of human toxocariasis in Jos, Plateau State, Nigeria. Memórias do Instituto Oswaldo Cruz 95: 147-149, 2000.

2. Alonso JM, Bojanich MV, Chamorro M, Gorodner JO. Toxocara seroprevalence in children from a subtropical city in Argentina. Revista do Instituto de Medicina Tropical de São Paulo 42: 235237, 2000

3. Baboolal S, Rawlins SC. Seroprevalence of toxocariasis in schoolchildren in Trinidad. Transaction Royal Tropical Medicine and Hygiene 96: 139-143, 2002.

4. Beaver PC, Snyder H. Carrera G. Chronic eosinophilia due to visceral larva migrans: report of three cases. Pediatrics 9:7-19, 1952.

5. Cilla G, Perez-Trallero E, Gutierrez C, Part C, Gomariz M. Seroprevalence of Toxocara infection in middle-class and disadvantaged children in northern Spain (Gipuzkoa, Basque Cauntry). European Journal of Epidemiology 12: 541-543, 1996.

6. De Savigny DH. In vitro maintenance of Toxocara canis larvae and a simple method for the production of Toxocara ES antigen for use in serodiagnostic tests for visceral larva migrans. Journal of Parasitology 61: 781-782, 1975.

7. De Savigny DH, Voller A. ELISA for toxocariasis using larval secretory antigens. Transaction Royal Society of Tropical Medicine and Hygiene 73: 106-115, 1978.

8. De Savigny DH, Voller A, Woodruff AW, Toxocariasis: serological diagnosis by enzyme immunoassay. Journal of Clinical Pathology 32: 284-288, 1979.
9. Elefant GR, Jacob CMA, Kanashiro EHY, Peres, BA. Toxocaríase. In: Ferreira AW, Ávila SLM (eds) Diagnóstico laboratorial das Principais doenças infecciosas e auto-imunes. $2^{\mathrm{a}}$ edição Guanabara Koogan. Rio de Janeiro, p. 323-332, 2001.

10. Gueglio B, de Gentile L, Nguyen JM, Achard J, Chabasse D, Marjolet M. Epidemiological approach to human toxocariasis in westwern France. Parasitology Research 80: 531-536, 1994.

11. Kanamura HY, Hoshino-Shimizu S, Silva LC. Solubilization of antigen S. mansoni adult worms for the passive hemagglutination test. Revista do Instituto de Medicina Tropical de São Paulo 23: 92-95, 1981.

12. Lowry VH, Rosembrouch NJ, Farr AL, Randall RJ. Protein measurement with the folin phenol reagent. Journal of Biological Chemistry 193: 265-271, 1956.

13. Lynch NR, Hagel I, Vargas V, Rotundo A, Varela MC, Di prisco MC, Hodgen AN. Comparable seropositivity for ascariasis and toxocariasis in tropical slum children. Parasitololgy Research 79: 547-550, 1993.

14. Nunes CM, Tundisi RN, Garcia JF, Heinemann MB, Ogassawara S, Richtzenhain LJ. Cross-reaction between Toxocara canis and Ascaris suum in the diagnosis of visceral larva migrans by western blotting technique. Revista do Instituto de Medicina Tropical de São Paulo 39: 1-8, 1997.

15. Nunes CM, Tundisi RN, Heinemann MB, Ogassawara S, Richtzenhain LJ. Toxocariasis: serological diagnosis by indirect 
antibody competition ELISA. Revista do Instituto de Medicina Tropical de São Paulo 41: 95-100, 1999.

16. Radman NE, Archelli SM, Fonrouge RD, del V Guardis M, Linzitto OR. Human toxocariasis. Its seroprevalence in the city of La Plata. Memórias do Instituto Oswaldo Cruz 95: 281-285; 2000.

17. Shields JA. Ocular toxocariasis. A review. Survey of Ophtalmolology 28: 361-381, 1984.

18. Silva FM, Leão ME, Mendonça HFS, Pereira FEL. Prevalence of anti-Toxocara antibodies in a random sample of impatients at a children's hospital in Vitória, Espírito Santo, Brazil. Revista do Instituto de Medicina Tropical de São Paulo 40: 1-6, 1998.

19. Yamasaki H, Araki K, Chooi Lim PK, Zasmy N, Wah Mak J, Taib $\mathrm{R}$, Aoki T. Development of a highly specific recombinant Toxocara canis second-stage larva excretory-secretory antigen for immunodiagnosis of human toxocariasis. Journal of Clinical Microbiology 38: 1409-1413, 2000. 